\title{
USE OF YELLOW OLEANDER (THEVETIA PERUVIANA) SEED OIL BIODIESEL AS CETANE AND LUBRICITY IMPROVER FOR PETRODIESEL
}

\author{
D. K. Sarmah and D. C. Deka* \\ Department of Chemistry, Gauhati University, Guwahati 781014, Assam, India \\ *E-mail: dcdeka1102@gmail.com
}

\begin{abstract}
The performance of a cetane and lubricity improver in a diesel engine can be evaluated respectively by cetane number and average wear scar diameter. Cetane number is a measurement of the combustion quality of diesel fuel; on the other hand, the lubricity of diesel fuel is indicated by the wear scar diameter value. An optimum level of cetane number and lubricity is very much essential for the smooth functioning of a diesel engine. As biodiesel possesses a higher value of cetane number and good lubricity value, therefore it may be used as cetane and lubricity improver in conventional petrodiesel. In this study, the yellow oleander seed oil is converted to fatty acid methyl esters (YOME) and fatty acid ethyl esters (YOEE) by transesterification reaction using a heterogeneous catalyst in methanol and ethanol, respectively. The yields of biodiesels obtained are $96 \mathrm{wt} \%$ for YOME and $94 \mathrm{wt} \%$ for YOEE at ambient temperature in $3 \mathrm{~h}$ and $3.5 \mathrm{~h}$ respectively. In this work, YOME and YOEE are used successfully as cetane and lubricity improver in petrodiesel and biodiesel blends. We are draining out our existing energy resources and therefore, biodiesel has evolved as an alternative fuelling option, and it has a big role to play in the future.
\end{abstract}

Keywords: Cetane Improver, Lubricity Improver, Transesterification, Thevetia peruviana, Biodiesel.

(C) RASĀYAN. All rights reserved

\section{INTRODUCTION}

The world's energy demand is increasing geometrically as evidenced in the increasing demand for fuels for transportation, industrial as well as domestic activities. This escalating energy demand continues notwithstanding the alarming environmental pollution and green house effects resulting from the extensive use of petroleum-based fuels. ${ }^{1}$ As resources of petroleum-based fuels are nonrenewable in nature therefore, there is an urgent need for searching an alternative energy resource that is renewable and environmentally friendly as a substitute to the conventional fossil fuel. In this context, biodiesel is regarded as a viable alternative because of its renewability, biodegradability, non-toxicity and carbon neutrality nature. ${ }^{2-5}$ Biodiesel provides lower toxicity and higher cetane number thereby improving engine performance and reducing emissions. ${ }^{6}$ Biodiesel produces significantly less amount of unburned hydrocarbon vapor. ${ }^{7}$ Up to $20 \%$ blending of biodiesel with conventional petrodiesel can be used in a diesel engine without modification of engine parts. ${ }^{8-10}$ Also the B6 to B20 blends are covered by the ASTM D 7467 specifications.

Cetane number is a measure of the ignition quality of the diesel fuel and is determined by a standard engine test as specified by ASTM D 613 method. The ignition quality is determined by measuring the ignition delay, which is the period between the time of injection and the start of combustion of the fuel. ${ }^{11}$ In recent times, there is an upward trend in the use of biodiesel, cetane improver and their blends with petrodiesel that decreases the price of biodiesel retaining some of the advantages of biodiesel. The growing increase in biodiesel consumption is due to various factors such as decreasing dependency on imported crude oil, providing a market for renewable and biodegradable biodiesel, reducing global warming, increasing lubricity, reducing objectionable emissions and particulate emission from a diesel engine. The cetane improver increases the cetane number of petrodiesel by bettering fuel ignition characteristics in the combustion chamber of the diesel engine. The main benefits of cetane number

Rasayan J. Chem., 12(3), 1547-1556(2019)

http://dx.doi.org/10.31788/RJC.2019.1235293

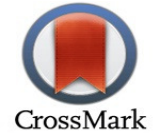


improvers are shortened ignition delay, discouraging premature combustion, improved cold starts in the region of higher altitude, reduced knocking, fewer misfire, reduced fuel consumption, lower engine wear and minimum deposits. ${ }^{12}$

Usually, in petroleum refinery, alkyl nitrates (e.g. 2-Ethylhexyl nitrate) and di-tert-butyl peroxide are used as cetane improver. ${ }^{13}$ Various commercial cetane improvers available in the market are Lubrizol ${ }^{\circledR}$ 8090, YTD-11, Power Service Diesel Kleen Fuel Additives, FPPF 8+, Innospec's CI-0801, and Innospec's CI-0808, etc. As biodiesels possess higher cetane number, therefore they can be used as cetane improver. The main advantages of biodiesels over commercial cetane improvers are that, they will reduce $\mathrm{SO}_{\mathrm{x}}, \mathrm{NO}_{\mathrm{x}}$ emission, reduce particulate matter, decrease the toxicity of fuel, increase lubricity as well.

Lubricity is an inherent property of a fuel which is measured by the wear scar produced on an oscillating ball from contact with a stationary plate immersed in the fuel and operating under closely controlled conditions. The determination of lubricity in diesel fuel is done by ASTM D 6079 or IS 1448 [P 149] method using the high-frequency reciprocating rig (HFRR). ${ }^{14,15}$ Optimum lubricity of petrodiesel minimizes the friction between the surfaces. Without proper lubricity, many internal engine parts including fuel pumps and injectors are prone to excessive wear and metal damage. The results of such wear are inadequate performance, reduced service life, and high replacement costs. ${ }^{16}$ The fuel itself is a part of the modern diesel engine lubrication process. Petrodiesel contains sulphur compounds naturally that provide lubricity. But due to environmental regulation across the world sulphur should be removed from the fuel before it can be marketed. Therefore desulphurization via hydrotreatment of diesel fuel is done for removing sulphur and hence lubricity of the fuel decreases. For maintaining proper lubricity of the diesel, lubricity additive must be added to prevent excessive engine wear. ${ }^{17}$ Various commercial lubricity improvers available in the market are Opti-Lube XPD, HiTEC®4171, OLI 9000 and OLI 9900 SERIES, Rev-x DIS 1601 Distance+, Power Service 03128-04 Diesel Kleen, Hot Shot's Secret P040464Z, Stanadyne Performance Formula Diesel Fuel Additive, etc. Addition of only 2\% biodiesel to petrodiesel gives maximum lubricity benefits as reported by Stanadyne Automotive Corporation. ${ }^{18}$ The aim of this work is to examine the potential of yellow oleander biodiesels, YOME and YOEE as cetane improver as well as lubricity improver in petrodiesel.

\section{Materials and Methods}

\section{EXPERIMENTAL}

Mature fruits of yellow oleander plants were collected from different places of Kamrup (Metro and Rural) districts of Assam in summer and winter seasons. Yellow oleander plant fruits were manually de-shelled after removing the pulp to get the kernels which were sun-dried before being crushed for solvent extraction. Seed oils were extracted from the crushed kernels by stirring magnetically a mixture of the kernel with petroleum ether $(10 \mathrm{~mL} / \mathrm{g})$ at ambient temperature for $3 \mathrm{~h}$. The solid residue was removed by filtration and the solvent from the filtrate was evaporated in a rotary vacuum evaporator to yield the crude oil. The extracted oil was purified by column chromatography over silica gel (60-120 mesh) using a mixture of petroleum ether $\left(40-60{ }^{\circ} \mathrm{C}\right)$ and ethyl acetate (20:1) as the eluent. Seed oil transesterification was carried out with methanol and ethanol using ashes of the trunk of Musa balbisiana Colla as the catalyst to afford yellow oleander methyl ester (YOME) and yellow oleander ethyl ester (YOEE), respectively. ${ }^{19,20}$ The petrodiesel needed for the study was collected from Guwahati Refinery, IOCL, Noonmati. It was the neat diesel obtained after de-sulphurization in the hydro-treating unit, free from other known additives (Cetane or Lubricity improver). 2-Ethylhexyl Nitrate (2-EHN, Fig.-1), a cetane improver used for the study was supplied by Deepak Chemicals, Gujarat. The neat diesel used in the study had cetane number 46 and wear scar diameter of 334 microns.

For cetane improver study, YOME was blended with neat diesel as ND00 (Pure Neat diesel), YOMEND500 (500 ppm YOME in neat diesel), YOMEND700 (700 ppm YOME in neat diesel), YOMEND900 (900 ppm YOME in neat diesel), YOMEND1000 (1000 ppm YOME in neat diesel), YOMEND2000 (2000 ppm YOME in neat diesel), and YOMEND3000 (3000 ppm YOME in neat diesel). Similarly, YOEE was blended with neat diesel as ND00 (Pure Neat diesel), YOEEND500 (500 ppm YOEE in neat diesel), YOEEND700 (700 ppm YOEE in neat diesel), YOEEND900 (900 ppm YOEE in neat diesel), YOEEND1000 (1000 ppm YOEE in neat diesel), YOEEND2000 (2000 ppm 
YOEE in neat diesel), YOEEND3000 (3000 ppm YOEE in neat diesel), YOEEND4000 (4000 ppm YOEE in neat diesel), and YOEEND5000 (5000 ppm YOEE in neat diesel).

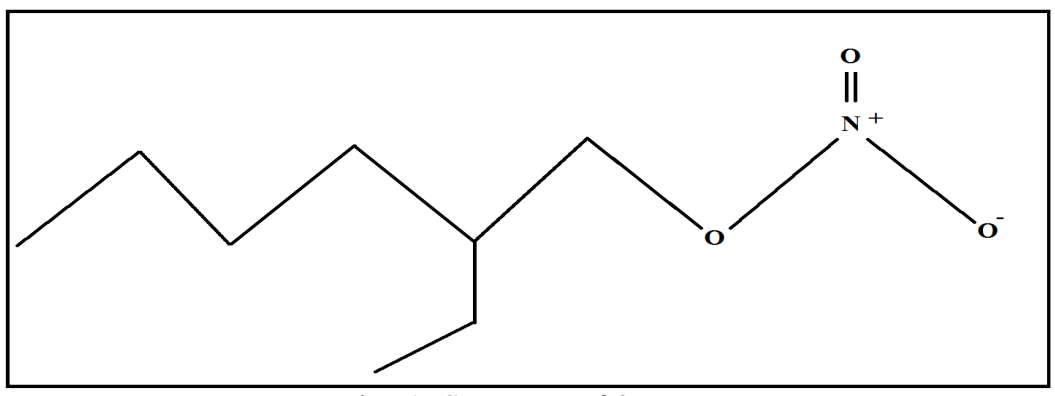

Fig.-1: Structure of 2-EHN

For comparing the effectiveness of 2-EHN as cetane improver, neat diesel was blended with 2-EHN as ND00 (Pure Neat diesel), EHNND500 (500 ppm 2-EHN in neat diesel), EHNND700 (700 ppm 2-EHN in neat diesel), EHNND900 (900 ppm 2-EHN in neat diesel), EHNND1000 (1000 ppm 2-EHN in neat diesel), and EHNND1100 (1100 ppm 2-EHN in neat diesel).

For lubricity study YOME was blended with neat diesel as ND00 (Pure Neat diesel), YOMEBD50 (50 ppm YOME in neat diesel), YOMEBD100 (100 ppm YOME in neat diesel), YOMEBD200 (200 ppm YOME in neat diesel), YOMEBD300 (300 ppm YOME in neat diesel), YOMEBD500 (500 ppm YOME in neat diesel), YOMEBD1000 (1000 ppm YOME in neat diesel), YOMEBD3000 (3000 ppm YOME in neat diesel), and YOMEBD5000 (5000 ppm YOME in neat diesel). Similarly, YOEE was blended with neat diesel as ND00 (Pure Neat diesel), YOEEBD50 (50 ppm YOEE in neat diesel), YOEEBD100 (100 ppm YOEE in neat diesel), YOEEBD200 (200 ppm YOEE in neat diesel), YOEEBD300 (300 ppm YOEE in neat diesel), YOEEBD500 (500 ppm YOEE in neat diesel), YOEEBD1000 (1000 ppm YOEE in neat diesel), YOEEBD3000 (3000 ppm YOEE in neat diesel), and YOEEBD5000 (5000 ppm YOEE in neat diesel).

\section{Test Method for Cetane Number}

The cetane number test was performed using a standard Cooperative Fuels Research (CFR) engine (Compression-Ignition CFR Engine, Make- M/S Core Laboratory, USA) shown in Fig.-2. The test method adopted for the determination of cetane number was ASTM D 613.

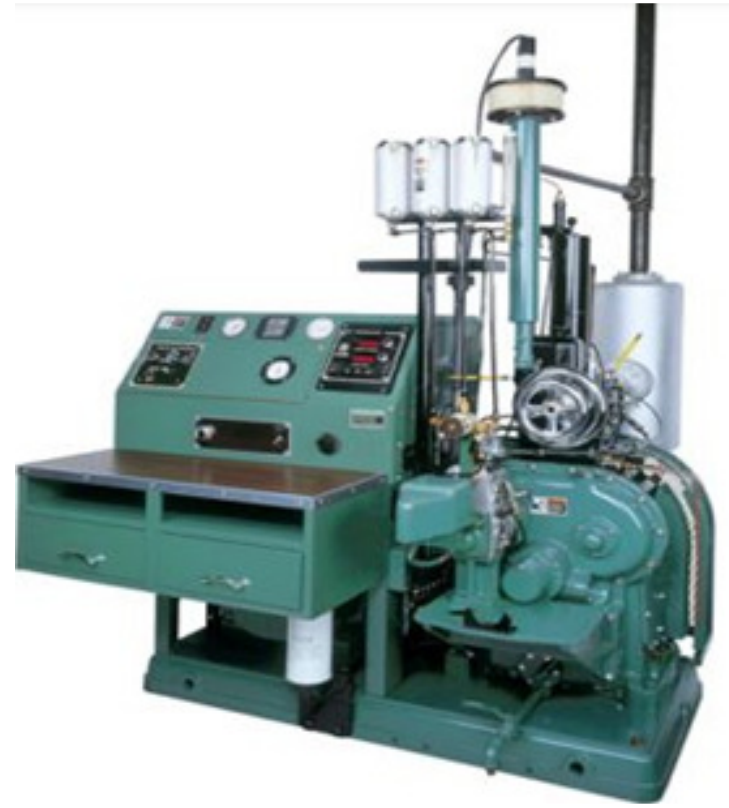

Fig.-2: Image of a Typical CFR Cetane Engine 


\section{Calculation of Cetane Number}

Cetane number of a sample can be calculated by the following equation: ${ }^{11}$

$$
C N_{S}=C N_{L R F}+\left(\frac{H W_{S}-H W_{L R F}}{H W_{H R F}-H W_{L R F}}\right)\left(C N_{H R F}-C N_{L R F}\right)
$$

where, $\mathrm{CN}_{\mathrm{S}}=$ Cetane number of the test sample; $\mathrm{CN}_{\mathrm{LRF}}=$ Cetane number of low reference fuel; $\mathrm{CN}_{\mathrm{HRF}}=$ Cetane number of high reference fuel; $\mathrm{HW}_{\mathrm{s}}=$ Handwheel reading of the sample; $\mathrm{HW}_{\mathrm{LRF}}=$ Handwheel reading of low reference fuel and $\mathrm{HW}_{\mathrm{HRF}}=$ Handwheel reading of high reference fuel.

The standard operating conditions of the cetane engine is shown in Table-1.

Table-1: Standard Operating Conditions of Cetane Engine ${ }^{11}$

\begin{tabular}{c|l|l}
\hline S. No. & \multicolumn{1}{c|}{ Parameters } & \multicolumn{1}{c}{ Operating Conditions } \\
\hline 1 & Engine Speed & $(900 \pm 9) \mathrm{rpm}$ \\
\hline 2 & Coolant Temperature & $100 \pm 2{ }^{\circ} \mathrm{C}$ \\
\hline 3 & Lube Oil Temperature & $57 \pm 8{ }^{\circ} \mathrm{C}$ \\
\hline 3 & Intake Air Temperature & $66 \pm 0.5{ }^{\circ} \mathrm{C}$ \\
\hline 4 & Injection Timing (BTDC) & 13.0 degree \\
\hline & Valve Clearance: & \\
& Intake valve(cold) & 0.004 inch \\
5 & Exhaust valve(cold) & 0.014 inch \\
& Final clearance setting (hot \& running) & $(0.008 \pm 0.001)$ inch \\
\hline 6 & Lube oil Pressure & 25 to $30 \mathrm{psi}$ \\
\hline 7 & Reference Fuel & T-Fuel and U-Fuel \\
\hline 8 & Standard Injection advance and Ignition delay & $13 \pm 0.2$ degree \\
\hline 9 & Fuel Pump Inlet Pressure & $(635 \pm 25) \mathrm{mm}$ \\
\hline 10 & Injection Flow Rate & $13.0 \pm 0.2 \mathrm{~mL} / \mathrm{min}$ \\
\hline
\end{tabular}

Cetane numbers of reference fuel used in the study

a. U-16 (U-Fuel) : 19.4

b. T-23 (T-Fuel) : 76.0

Blending Percentage of Reference Fuel and Cetane Number

\begin{tabular}{c|c|c}
\hline Percentage of T-23 & Percentage of U-16 & Cetane number \\
\hline 45 & 55 & 44.8 \\
\hline 54 & 46 & 49.9 \\
\hline 63 & 37 & 55.0 \\
\hline
\end{tabular}

\section{Test method for Lubricity}

The test methods for the determination of lubricity in diesel fuel are ASTM D 6079 or IS 1448 [P 149] using the high-frequency reciprocating rig (HFRR). ${ }^{14,15}$ In the method, $2 \mathrm{~mL}$ fuel sample is placed in the test reservoir of an HFRR instrument (Make: PCS instruments, UK, Fig.-3) and adjusted to temperatures $60{ }^{\circ} \mathrm{C}$. The load applied to the steel ball was $200 \mathrm{~g}$. The ball is allowed to rub on the disk with a $1 \mathrm{~mm}$ stroke at a frequency of $50 \mathrm{~Hz}$ for 75 minutes. The ball is then removed and cleaned. The dimensions of the major and minor axes of the wear scar are measured under 100x magnification and recorded. The test should be run at the accepted humidity limit with respect to a temperature which is represented by a graph shown in Fig.4. Ideal test conditions are given in Table-2.

\section{Wear Scar Diameter (WSD)}

The lubricity of fuel under study is determined by measuring average wear scar diameter in microns with the help of 100x magnification photomicroscope. The wear scar diameter of the test sample is measured in the $\mathrm{X}$ and $\mathrm{Y}$ directions.

\section{Friction Coefficient $(\boldsymbol{\mu})$}

If the friction is proportional to the load, the friction coefficient $(\mu)$ can be expressed as:

$$
\mu=\mathrm{F} / \mathrm{P}
$$


RASĀYAN J. Chem.

Vol. 12 | No. 3 |1547 - 1556| July - September | 2019

where, $\mathrm{F}$ is the frictional force and $\mathrm{P}$ is the applied load in Newton. A higher value of friction coefficient generally indicates poor lubrication and more wear.

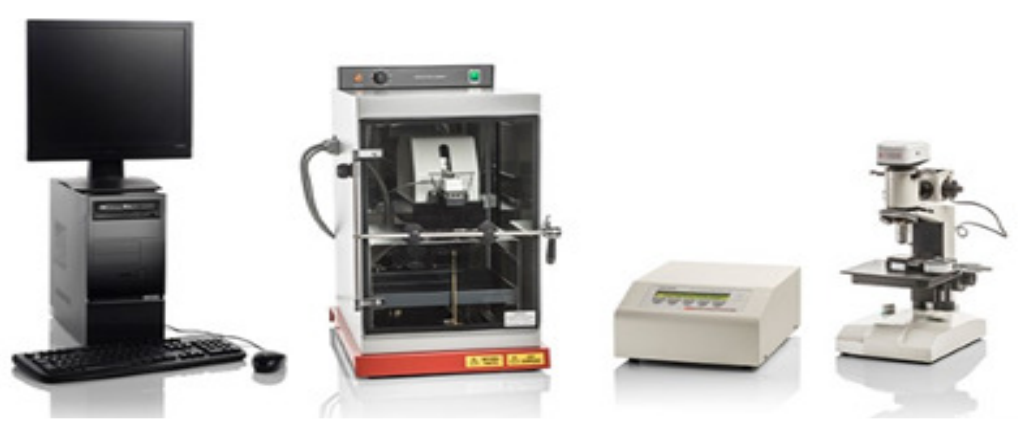

Fig.-3: Image of HFRR Instrument with Accessories

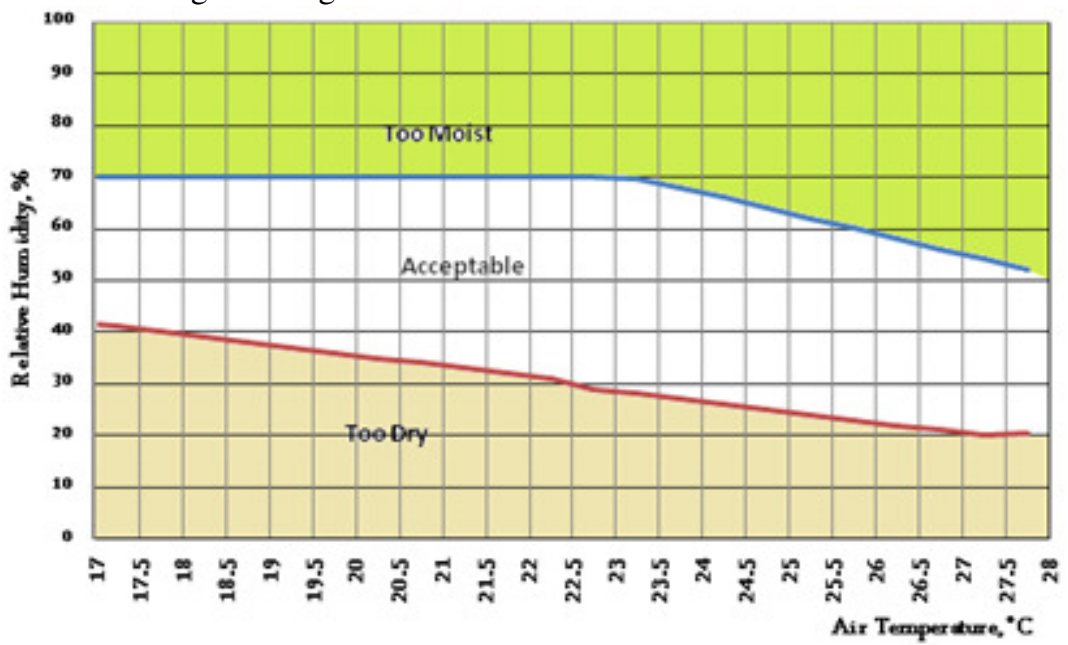

Fig.-4: Acceptable Humidity Limit with Respect to Temperature for Lubricity Determinations

Using the High-Frequency Reciprocating Rig (HFRR) Test

Table-2: The Ideal Test Conditions for HFRR ${ }^{14,15}$

\begin{tabular}{c|c|c}
\hline Sl. No. & Parameters & Test Conditions \\
\hline 1 & Fluid volume $(\mathrm{mL})$ & $2 \pm 0.2$ \\
\hline 2 & Fluid temperature $\left({ }^{\circ} \mathrm{C}\right)$ & $60 \pm 2$ \\
\hline 3 & Bath surface area $\left(\mathrm{mm}^{2}\right)$ & $600 \pm 100$ \\
\hline 4 & Stroke length $(\mathrm{mm})$ & $1 \pm 0.02$ \\
\hline 5 & Frequency $(\mathrm{Hz})$ & $50 \pm 1$ \\
\hline 6 & Applied load $(\mathrm{g})$ & $200 \pm 1$ \\
\hline 7 & Test duration $(\mathrm{min})$ & $75 \pm 0.1$ \\
\hline 8 & Ball diameter $(\mathrm{mm})$ & 6.00 \\
\hline 9 & Specimen steel & AISI E-52100 steel \\
\hline 10 & Surface finish (ball) & Ra $<0.05 \mu \mathrm{m}$ \\
\hline 11 & Hardness (ball) & $58-66$ Rockwell "C" scale \\
\hline 12 & Hardness (plate) & $190-210$ "HV $30 "$ \\
\hline 13 & Surface finish (plate) & $R a<0.02 \mu \mathrm{m}$ \\
\hline 14 & Relative humidity $(\%)$ & $>30$ \\
\hline
\end{tabular}

Film Thickness (\%)

The film thickness (\%) is obtained from the HFRR instrument. A lower value of film thickness indicates high frictional force as well as high wear. The effects of YOME and YOEE as cetane and lubricity improver were tested with respect to cetane number, wear scar diameter, film thickness percentage and coefficient of friction. The cetane number and lubricity of the different blends were conducted as per standard test procedure. 


\section{RESULTS AND DISCUSSION}

In this study, the highest percentage of biodiesel (YOME and YOEE) added to the petrodiesel was $0.5 \%$ $(5000 \mathrm{ppm})$ only. Therefore, changes in fuel properties necessitating diesel engine modification were considered insignificant.

\section{Cetane Number of YOME and YOEE Blends}

The cetane numbers of various blends of neat diesel with 2-EHN, YOME and YOEE are shown in Table3 , Table-4 and Table-5 respectively. A comparison of these data is graphically shown in Fig.-5.

Table-3: Cetane Number of 2-EHN and Neat Diesel Blends

\begin{tabular}{c|c|c}
\hline Blends & 2-EHN Blending $(\mathrm{ppm})$ & Cetane Number \\
\hline ND00 & 0 & 46.0 \\
\hline EHNND500 & 500 & 49.0 \\
\hline EHNND700 & 700 & 50.1 \\
\hline EHNND900 & 900 & 51.4 \\
\hline EHNND1000 & 1000 & 51.8 \\
\hline EHNND1100 & 1100 & 52.0 \\
\hline
\end{tabular}

Table-4: Cetane Number of YOME and Neat Diesel Blends

\begin{tabular}{c|c|c}
\hline Blends & YOME Blending $(\mathrm{ppm})$ & Cetane Number \\
\hline ND00 & 0 & 46.0 \\
\hline YOMEND500 & 500 & 46.5 \\
\hline YOMEND700 & 700 & 46.8 \\
\hline YOMEND900 & 900 & 47.0 \\
\hline YOMEND1000 & 1000 & 47.2 \\
\hline YOMEND2000 & 2000 & 49.0 \\
\hline YOMEND3000 & 3000 & 51.4 \\
\hline
\end{tabular}

Table-5: Cetane Number of YOEE and Neat Diesel Blends

\begin{tabular}{c|c|c}
\hline Blends & YOEE Blending $(\mathrm{ppm})$ & Cetane Number \\
\hline ND00 & 0 & 46.0 \\
\hline YOEEND500 & 500 & 46.2 \\
\hline YOEEND700 & 700 & 46.3 \\
\hline YOEEND900 & 900 & 46.8 \\
\hline YOEEND1000 & 1000 & 47.0 \\
\hline YOEEND2000 & 2000 & 47.2 \\
\hline YOEEND3000 & 3000 & 47.3 \\
\hline YOEEND4000 & 4000 & 47.3 \\
\hline YOEEND5000 & 5000 & 47.4 \\
\hline
\end{tabular}

Comparison of cetane number of 2-EHN, YOME and YOEE blends with neat diesel (Fig.5) shows that the effectiveness of 2-EHN as cetane improver is the best amongst all the three. Again in between YOME and YOEE, the effectiveness of YOME as cetane improver is better than YOEE. A blending of $1000 \mathrm{ppm}$ of 2-EHN, YOME and YOEE can increase Cetane Number from 46.0 of neat diesel to 51.8, 47.2 and 47.0 respectively. From the data shown in the tables it is clear that $500 \mathrm{ppm}$ of 2 -EHN in petrodiesel effects an increase of cetane number from 46 to 49 (Table 3). To achieve the same increment in cetane number with YOME, $2000 \mathrm{ppm}$ would be required (Table 4). With YOEE, increase in cetane number up to 49 could not be achieved even after the blending with $5000 \mathrm{ppm}$ (Table 5). When compared with 2-EHN, it is observed that a larger quantity of YOME is required to effect the similar increment in cetane number. However, YOME itself is fuel, and it is free from polluting elements such as $\mathrm{N}$ and S. Considering all factors together and overall effects in totality, it can be opined that YOME and YOEE can be considered as a better alternative to synthetic cetane improvers like 2-EHN.

\section{Lubricity Study of YOME and YOEE Blends}

The average wear scar diameter, friction coefficient and film thickness as determined by HFRR instrument for YOME and YOEE blends are recorded in Table-6 and 7, respectively. 
RASĀYAN J. Chem.

Vol. 12 | No. 3 |1547 - 1556| July - September | 2019

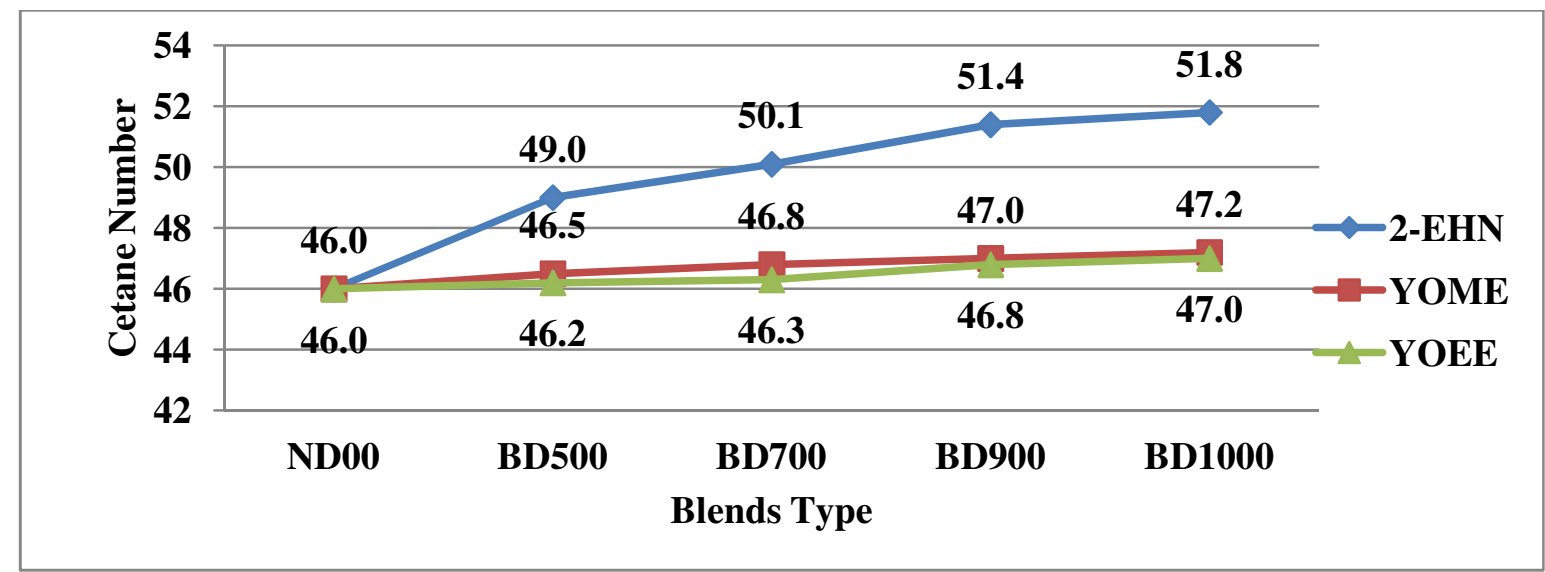

Fig.-5: Comparison of Cetane Number Improvement with 2-EHN, YOME and YOEE Additives Blended with Neat Diesel

Table-6: Test Results of Lubricity, Neat Diesel Blended with YOME

\begin{tabular}{|c|c|c|c|c|c|c|c|}
\hline $\begin{array}{l}\stackrel{0}{0} \\
\hat{\theta} \\
\frac{0}{0} \\
\frac{0}{n}\end{array}$ & 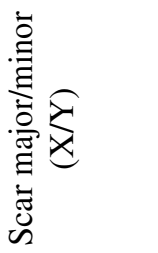 & 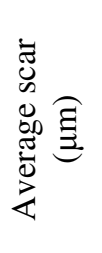 & 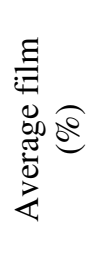 & 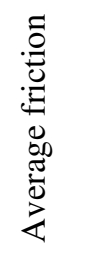 & 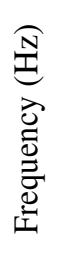 & 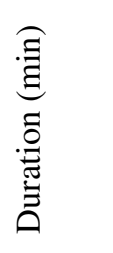 & 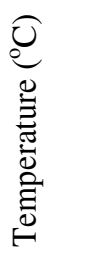 \\
\hline ND00 & $351 / 317$ & 334 & 17.2 & 0.235 & \multirow{10}{*}{50.0} & \multirow{10}{*}{75.0} & \multirow{10}{*}{59.9} \\
\hline YOMEBD50 & $335 / 298$ & 316 & 19.8 & 0.219 & & & \\
\hline YOMEBD100 & $333 / 285$ & 309 & 28.1 & 0.203 & & & \\
\hline YOMEBD200 & $304 / 253$ & 278 & 35.6 & 0.197 & & & \\
\hline YOMEBD300 & $298 / 246$ & 272 & 37.9 & 0.193 & & & \\
\hline YOMEBD500 & $290 / 236$ & 263 & 42.5 & 0.189 & & & \\
\hline YOMEBD1000 & $245 / 199$ & 222 & 76.2 & 0.172 & & & \\
\hline YOMEBD3000 & $241 / 186$ & 213 & 80.6 & 0.168 & & & \\
\hline YOMEBD5000 & $233 / 183$ & 208 & 83.5 & 0.147 & & & \\
\hline YOME & $211 / 165$ & 188 & 87.9 & 0.106 & & & \\
\hline
\end{tabular}

Table-7: Test Results of Lubricity, Neat Diesel Blended with YOEE

\begin{tabular}{|c|c|c|c|c|c|c|c|}
\hline $\begin{array}{l}\stackrel{\Xi}{2} \\
\hat{\theta} \\
\frac{0}{0} \\
\frac{0}{\infty}\end{array}$ & 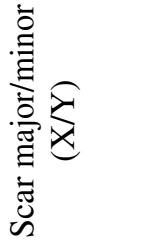 & 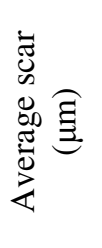 & 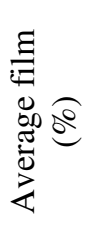 & 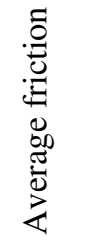 & 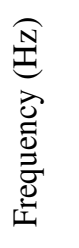 & 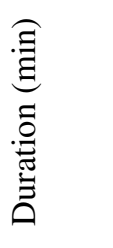 & 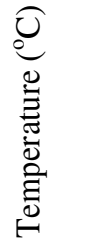 \\
\hline ND00 & $351 / 317$ & 334 & 17.2 & 0.235 & \multirow{10}{*}{50.0} & \multirow{10}{*}{75.0} & \multirow{10}{*}{59.9} \\
\hline YOEEBD50 & $331 / 283$ & 307 & 28.6 & 0.209 & & & \\
\hline YOEEBD100 & $326 / 273$ & 299 & 34.8 & 0.201 & & & \\
\hline YOEEBD200 & $287 / 237$ & 262 & 43.9 & 0.192 & & & \\
\hline YOEEBD300 & $275 / 230$ & 252 & 52.1 & 0.181 & & & \\
\hline YOEEBD500 & $244 / 188$ & 216 & 79.2 & 0.169 & & & \\
\hline YOEEBD1000 & $228 / 185$ & 206 & 84.2 & 0.154 & & & \\
\hline YOEEBD3000 & $220 / 170$ & 195 & 86.6 & 0.142 & & & \\
\hline YOEEBD5000 & $211 / 166$ & 188 & 88.2 & 0.133 & & & \\
\hline YOEE & $204 / 138$ & 171 & 91.4 & 0.085 & & & \\
\hline
\end{tabular}

From the data it is observed that the addition of only $50 \mathrm{ppm}$ of YOME and YOEE can reduce average USE OF YELLOW OLEANDER SEED OIL BIODIESEL 
wear scar diameter by 18 and 27 microns, respectively from 334 microns of neat diesel. Again blending of $5000 \mathrm{ppm}$ of YOME and YOEE can decrease average wear scar diameter by 126 and 146 microns, respectively. Blending of $5000 \mathrm{ppm}$ YOME with neat diesel can increase average film percentage from 17.2 of neat diesel to 83.5 of the blend, while decreasing average friction from 0.235 to 0.147 . In the case of $5000 \mathrm{ppm}$ YOEE blending, average film percentage increases to 88.2 and average friction decreases to 0.133 from that of neat diesel.

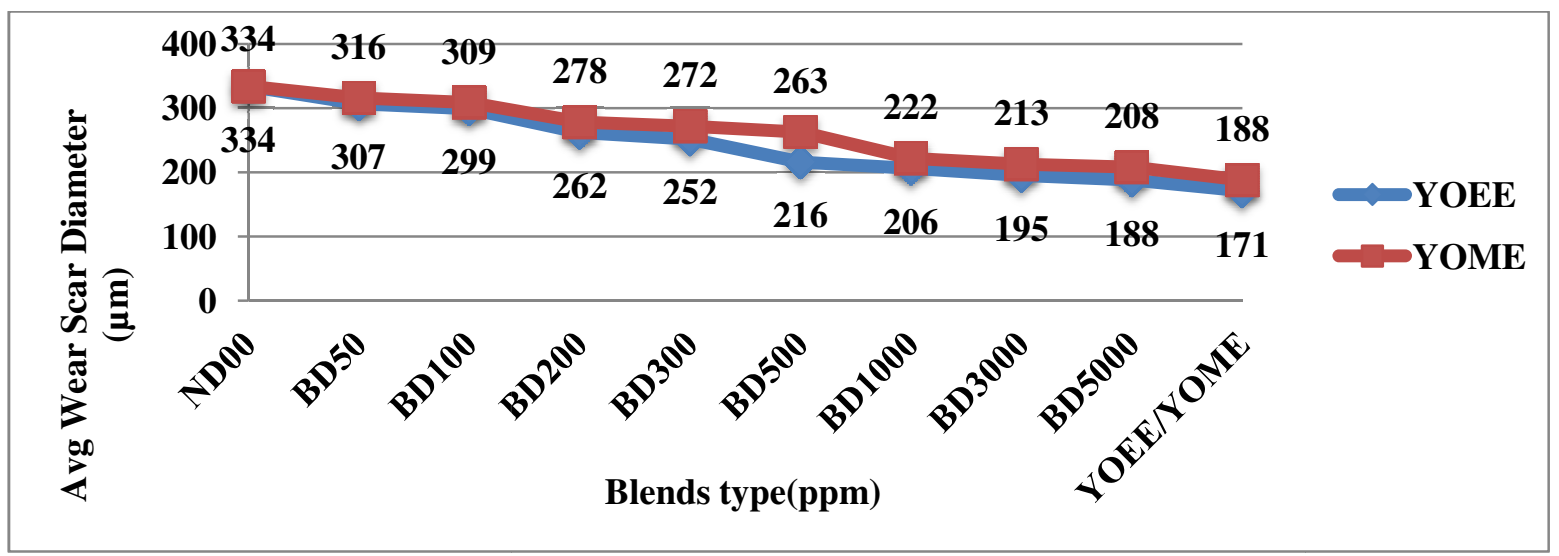

Fig.-6: Average WSD Vs Type of Blends with YOME \&YOEE

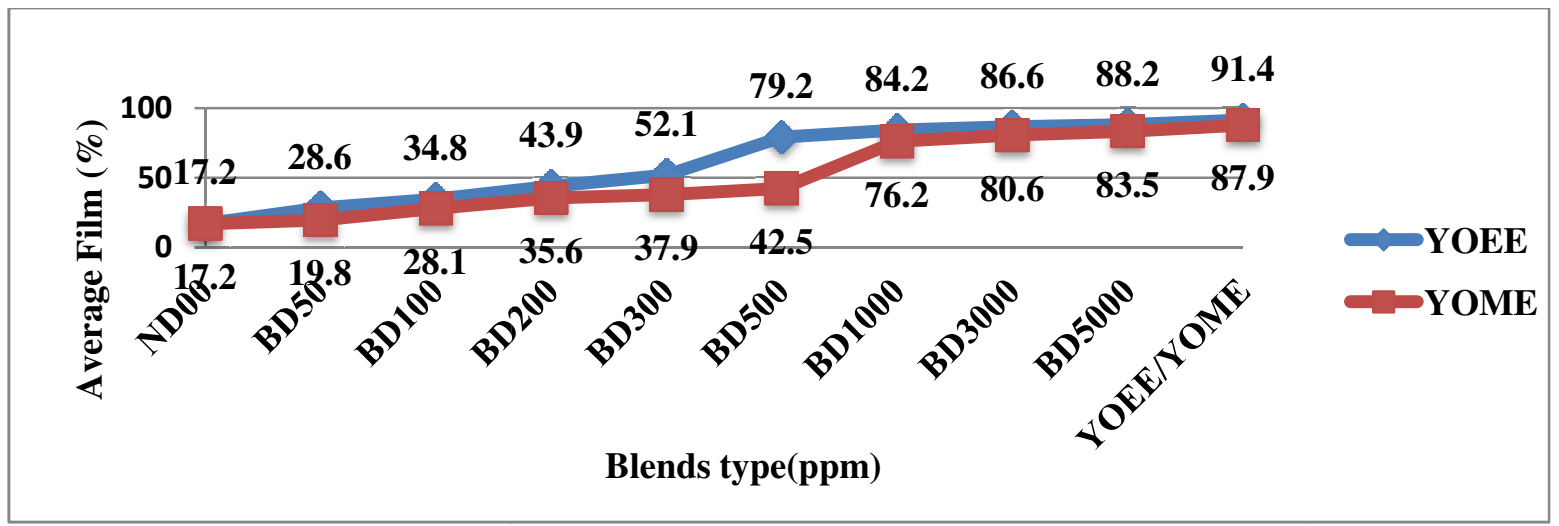

Fig.-7: Average Film (\%) Vs Type of Blends with YOME \&YOEE

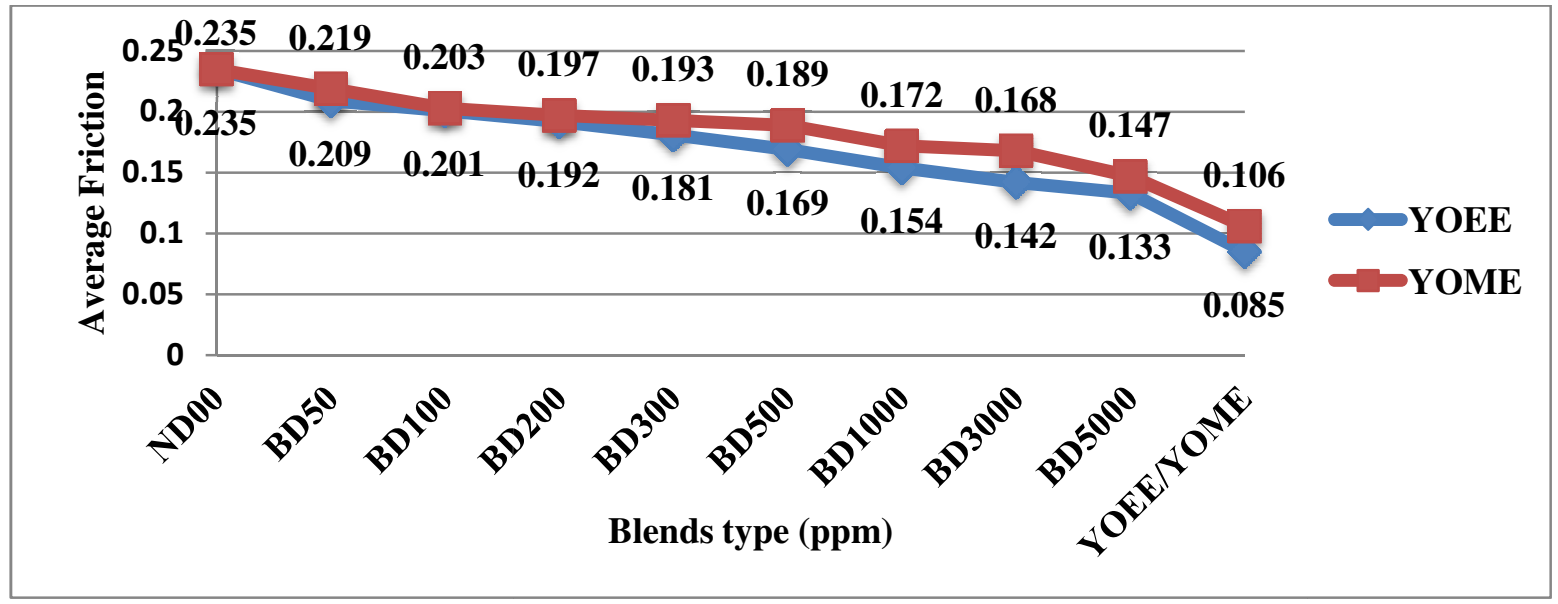

Fig.-8 : Average Friction Vs Type of Blends with YOME \&YOEE

Therefore, the test results imply that, both YOME and YOEE can reduce wear scar diameter and average friction, and increase average film thickness to an appreciable extent and thereby enhance the lubricity of 
the petrodiesel. Average wear scar diameter, average film percentage and average frictions of YOME and YOEE blends are compared graphically in Figures-6, 7 and 8, respectively. The wear scar diameter for Neat Diesel $(334 \mu \mathrm{m})$ is quite high in comparison to YOME $(188 \mu \mathrm{m})$ and YOEE $(171 \mu \mathrm{m})$. Addition of both YOME and YOEE gradually decreases the wear scar diameter and hence indicating an increase in lubricity.

In between YOME and YOEE, YOEE can act as a better lubricating additive in petrodiesel. A maximum blending of $5000 \mathrm{ppm}$ YOME or YOEE can decrease average wear scar diameter value to $126 \mu \mathrm{m}$ and $146 \mu \mathrm{m}$, respectively and thereby indicating enhancing lubricity of the neat diesel. The film thickness (\%) of neat diesel is found to be very low (only 17.2\%) in the study. The addition of YOME and YOEE as lubricity additive in different proportions to neat diesel enhances the film thickness to an appreciable extent. With the addition of $5000 \mathrm{ppm}$ of YOME or YOEE to neat diesel, the film thickness is increased to $83.5 \%$ and $88.2 \%$, respectively, indicating that there is barely any contact between the metal surfaces. The lubricant activity is associated with boundary film-forming properties, sulfur compounds, oxygenated compounds, and nitrogenous compounds present in the diesel fuel ${ }^{21,22}$.

The friction coefficient for neat diesel (0.235) is quite high in comparison to YOME (0.106) and YOEE (0.085). Addition of YOME or YOEE gradually decreases the friction coefficient which is indicative of an increased lubricity. A high friction coefficient is normally indicative of poor lubrication. From the study it is evident that in between YOME and YOEE, YOEE can act as a better lubricating additive in petrodiesel. A maximum blending of $5000 \mathrm{ppm}$ YOME or YOEE can decrease average friction coefficient value to 0.147 and 0.133 , respectively and thereby enhancing the lubricity of the neat diesel.

\section{CONCLUSION}

From the study, it is evident that yellow oleander methyl ester (YOME) and yellow oleander ethyl ester (YOEE), which were prepared from yellow oleander seed oil, are found to be effective cetane improver as well as a very good lubricity enhancer in petrodiesel when blended. YOME and YOEE can be used up to $0.5 \%$ with negligible effect on other parameters of the diesel fuel and at the same time enhancing cetane number as well as lubricity. Therefore, by using the required amount of YOME or YOEE as cetane and lubricity improver, we can help to protect our environment and natural resources to a large extent.

\section{ACKNOWLEDGMENT}

The authors wish to appreciate the members of Guwahati Refinery Quality Control Laboratory, Noonmati, for providing facility and their technical support during the study.

\section{REFERENCES}

1. R.R.E. Ana Godson and G.U. Bassey, International Journal of Sustainable and Green Energy, 4(3), 150(2015), DOI: $10.11648 /$ j.ijrse.20150404.14

2. B.R. Moser, G. Knothe, S.F. Vaughn and T.A. Isbell, Energy Fuels, 23, 4149(2009), DOI: 10.1021/ef900337g

3. J.K. Satyarthi, D.Srinivas and P. Ratnasamy, Energy Fuels, 23(4), 2273(2009), DOI: 10.1021/ef801011v

4. G. Knothe, Energy Fuels, 24(3), 2098(2010), DOI: 10.1021/ef9013295

5. E. Li, and V. Rudolph, Energy Fuels, 22(1), 145(2008), DOI: 10.1021/ef700290u

6. J.V. Gerpen, Fuel Processing Technology, 86(10), 1097(2005), DOI: 10.1016/j.fuproc.2004.11.005

7. R. Sundara Raman, G. Sankara Narayanan, N. Manoharan and S. Sendilvelan, RASAYAN J. Chem, 10(3), 944(2017), DOI: 10.7324/RJC.2017.1031664

8. P.K. Sahoo, L.M. Das, M.K.G. Babu and S.N. Naik, Fuel, 86(3), 448(2007), DOI: 10.1016/j.fuel.2006.07.025

9. H. Reheman and A.G. Phadatare, Biomass and Bioenergy, 27(4), 393(2004), DOI: 10.1016/j.biombioe.2004.03.002UUU

10. M. Canakci, A. Erdil and E. Arcaklioglu, Applied Energy, 83(6), 594(2006), DOI: 10.1016/j.apenengy.2005.05.003 
RASĀYAN J. Chem.

Vol. 12 | No. 3 |1547 - 1556| July - September | 2019

11. ASTM Standard D 613-08, Standard Test Method for Cetane Number of Diesel Fuel Oil, ASTM 5.05 (2010)

12. https://farmweeknow.com/blogs-benefits-high-cetane-diesel-fuel-3681

13. https://en.wikipedia.org/wiki/Cetane_number

14. ASTM Standard D 6079-04, Standard Test Method for Evaluating Lubricity of Diesel Fuels by the High- Frequency Reciprocating Rig(HFRR), ASTM 5.03 (2010)

15. Bureau of Indian Standards, Methods of Test for Petroleum And Its Products-Diesel Fuel-Assessment of Lubricity Using the High- Frequency Reciprocating Rig(HFRR), IS 1448, p.149(2014)

16. Jerome P. Sava, Fuel Oil News- Taking the Mystery out of Lubricity, April 30 (2016).

17. https://en.wikipedia.org/wiki/Lubricity

18. "Fuels for Diesel Engines- Diesel Fuel Injection Equipment manufacturers Common Position Statement", Signed by Delphi Diesel System, Stanadyne Automotive Corp., Denso Corporation, and Robert Bosch GmbH, issued June, (2000) (Retrieved via Google from a publication of the National Biodiesel Board, entitled Lubrication)

19. D.C. Deka and S. Basumatary, Biomass \& Bioenergy, 35(5), 1797(2011), DOI: 10.1016/j.biombioe.2011.01.007

20. D.C. Deka and N.N. Talukdar, Indian J. Traditional Knowledge, 6(1), 72 (2007).

21. G. Knothe, Energy Fuels, 22(2), 1358(2008), DOI: 10.1021/ef700639e

22. D.Margaroni, Industrial Lubrication and Tribology, 50(3), 108(1998), DOI: $10.1108 / 00368799810218026$

[RJC-5293/2019] 